\title{
Analysis of problem optimization of parameters maintenance process according to state with constant periodicity of control
}

\author{
Genadiy Zhyrov $^{1}$, Serhii Lienkov ${ }^{2}$, Yurii Husak ${ }^{3}$, Hennadii Banzak ${ }^{4}$, Igor Tolok ${ }^{5}$ \\ ${ }^{1}$ Department of the Radio Engineering and Radioelectronic Systems of Taras Shevchenko National University of \\ Kyiv, Ukraine, genna-g@ukr.net \\ ${ }^{2}$ Research Center Military Institute of Taras Shevchenko National University of Kyiv, Ukraine, \\ lenkov_s@ukr.net \\ ${ }^{3}$ Institute of the Armed Forces of Ukraine of Kyiv, Ukraine, y.husak1512@ gmail.com \\ ${ }^{4}$ Department Metrology and Metrological Support Odessa State Academy of Technical Regulation and Quality, \\ Ukraine, banzakoksana@gmail.com \\ ${ }^{5}$ Military Institute of Taras Shevchenko National University of Kyiv, Ukraine, s63010566s@ gmail.com
}

\begin{abstract}
One of the main indicators set in the design and modernization of complex technical facilities are indicators reliability and cost of operation. These indicators depend on the properties reliability and maintainability of the object, as well as on the parameters of maintenance system.
\end{abstract}

The article considers the problem of determining approaches to optimizing the parameters of MC process with a constant periodicity of control. Two optimization criteria are investigated: minimization of the specific cost operations of the object, which is determined at a given period of operation, while ensuring a given requirement for level of reliability object; and maximizing the coefficient of technical use while meeting the requirements for the level of reliability of the object. The results are necessary for the development of methods and algorithms for optimizing the parameters of different types of maintenance.

Key words: maintenance, maintenance as condition, simulation statistical modeling.

\section{INTRODUCTION}

Today, much attention is paid to increasing security measures in the operation of various complex technical facilities and systems, including special purpose. Reliable operation of electronic and radio electronic facilities and systems is ensured by high-quality operation of the maintenance and repair (MR) system. The need for maintenance is the timely replacement of elements that are in a pre-failure condition, which leads to improved performance of the object as a whole. Repairs are carried out in order to restore the serviceable or operational condition of object, as well as to restore the resource of whole object or its part [1-4].
Indicators of reliability and cost operation facilities depend on the properties of faultlessness and maintainability of the facility itself, as well as on parameters of maintenance system. Thus, there is a general problem of optimizing characteristics of object and parameters maintenance system. Determining the reliability of complex technical objects and their relationship with parameters of maintenance system on the basis statistical data is quite difficult. It is much easier and more efficient to conduct simulation statistical modeling to establish links between these parameters and the predicted indicators of reliability and cost of operation object itself.

In past, a large number of well-known scientists, including Kredentser B.P., Barzilovich E.Yu., Cox D., Smith V., Kashtanov V.O., Ushakov I.O., Barlow R., Proshan F. and others. Today, many scientists are also exploring the problem of optimizing the maintenance process for different types objects. Thus, in [5] a new variant of the selective service task (SMP) is considered for joint optimization of service planning and resource allocation tasks for several missions. The resulting SMP takes into account five joint solutions: selecting components for maintenance, selecting service levels performed on selected components, identifying gaps in service tasks, selecting repairmen, and assigning maintenance tasks to selected repairmen. The goal is to minimize the total cost of maintenance and pay for a service plan that guarantees a given reliability threshold. In [6], a model of service optimization is proposed taking into account both economic and structural dependencies between components. The effect of structural dependence on reliability of components was considered using a proportional hazard model. The model implements influencing factors, such as component components, system structure and production context. This supported a more accurate assessment of reliability. In [7], a stochastic optimization model for reducing long-term overall maintenance costs of complex systems is considered. The work is based on the fact that: 
Genadiy Zhyrov et al., International Journal of Emerging Trends in Engineering Research, 8(6), June 2020, 2606- 2611

optimization of cost model for complex multicomponent systems, based on the analysis of reliability different approaches to maintenance (periodic block and age) and the method of clustering maintenance actions to reduce the total cost of maintenance complex systems. In [8], in accordance with the tasks of optimizing maintenance, first select the most important components of the power system with renewable energy sources. Then a set of maintenance strategies for all critical components is proposed. The total cost of each maintenance strategy for all critical components is calculated as the sum of the costs of: operation, maintenance, environmental protection. The best service strategy for each critical component is selected by determining the lowest total cost of the various service strategies. In [9] the new method of optimum strategy of service difficult system taking into account the set restriction of reliability is considered. It is based on the method of direct analysis, which provides an accurate quantitative determination of the reliability highly reliable systems with maintenance. As a discrete service model in this article we consider a model where each serviced component can operate in one or more discrete service modes. In [10] we consider obtaining an optimal schedule of preventive maintenance of one element on the final segment on the basis of Bayesian models failure rate function. In [11] a new approach to modeling the maintenance of machines taking into account architecture of the park systems was developed. The architecture of fleet systems is considered, consisting of different types machines from different equipment manufacturers, working with different users, but supported by one repair shop. The essence of the approach is to jointly optimize solutions by level of repair, namely: by repair schedules, relocation, disposal and preventive maintenance, taking into account the structure of user costs and policy parameters in the shops. In [12] a new approach to cost-effective optimization of shutdown strategies for a set of repaired elements is presented. The optimization method consists of two stages. First, a new concept of matrix modeling is introduced to find space to solve this optimization problem. Second, a genetic algorithm is used to find a solution with minimal cost. It is shown that the combination of matrix modeling and genetic algorithm is a powerful method for quickly solving the optimization problem. In [13], the MINLP model is proposed, which represents a stochastic process of failures and repairs of the system in the form of a Markov chain with a continuous time, based on which the choice of redundancy and frequency of inspection and maintenance tasks is optimized for maximum profit. The model clearly takes into account all possible states of the system. Effective methods of decomposition and reduction of service scenarios are also offered. In [14], analyzed solutions to search problems and detection of objects in technical systems for various purposes. The developed rule can be extended to the case of a multi-alternative problem of testing hypotheses. In [15], an algorithm was developed for calculating the unconditional probability of detecting an object of observation during joint search and detection of objects in technical surveillance systems. It is shown that the joint search and detection of objects of observation using a uniformly optimal search strategy provides a higher unconditional probability of a correct decision.

\section{METHODOLOGY}

The problem of optimization maintenance (MC) parameters can be reduced to solving the problems: optimization by criterion $\min c_{\mathrm{e}}(1)$ and optimization by criterion $\max K_{\mathrm{ssa}}$ (2):

$$
\begin{aligned}
& T_{0}\left(E_{\mathrm{mc}}^{*}, U_{\mathrm{mc}}^{*}, T_{\mathrm{c}}^{*}\right) \geq T_{0}^{\mathrm{req}} ; c_{\mathrm{e}}\left(E_{\mathrm{mc}}^{*}, U_{\mathrm{mc}}^{*}, T_{\mathrm{c}}^{*}\right) \rightarrow \min \\
& T_{0}\left(E_{\mathrm{mc}}^{*}, U_{\mathrm{mc}}^{*}, T_{\mathrm{c}}^{*}\right) \geq T_{0}^{\text {req }} ; c_{\mathrm{e}}\left(E_{\mathrm{mc}}^{*}, U_{\mathrm{mc}}^{*}, T_{\mathrm{c}}^{*}\right) \rightarrow \min
\end{aligned}
$$

where: $T_{0}^{\text {req }}-$ requirement for level of reliability objects; $E_{\mathrm{mc}}^{*}, U_{\mathrm{mc}}^{*}$ and $T_{\mathrm{c}}^{*}$ - desired optimal values of $\mathrm{MC}$ parameters with a constant periodicity of control; $E_{\mathrm{mc}}$ - set elements that are serviced; $U_{\mathrm{mc}}$ - vector of levels that determine the need for maintenance of elements; $T_{\mathrm{c}}$ frequency of control; $K_{s s a}$ - is a steady state availability factor.

The parameters $E_{\mathrm{mc}}^{*}, U_{\mathrm{mc}}^{*}$ and $T_{\mathrm{c}}^{*}$, obtained as a result of solving problems (1) and (2), will be different.

The space in which the search for optimal values should be carried out $E_{\mathrm{mc}}^{*}, U_{\mathrm{mc}}^{*}$ and $T_{\mathrm{c}}^{*}$, in both problems is the same and is a Cartesian product of the following form:

$$
\left\{E_{\mathrm{mc}}\right\} \times[0,1]^{\mid E_{\mathrm{mc}}} \mid \times[0, \infty)
$$

where $\left\{E_{\mathrm{mc}}\right\}-$ is the set of all sets consisting elements that are part of set $E_{\mathrm{mc}} ;[0,1]^{\mid E_{\mathrm{mc}}} \mid$ - hypercube, each point in which is a vector dimension $\left|E_{\mathrm{mc}}\right|$, elements of vector are numbers belonging to the segment; $[0,1] ;[0, \infty)$ - numerical axis containing all positive numbers.

The generating element of the space (3) is a set of serviced elements $E_{\mathrm{mc}}$. The set $E_{\mathrm{mc}}$ is determined by the developer, and it includes the least reliable elements for which the defining parameters are known and there are means of measuring them. At the stage of development objects of technology for some potentially serviced elements, the defining parameters may still be unknown. However, such elements can be included in the set $E_{\mathrm{mc}}$ in order to test the feasibility in the future of additional studies to identify the defining parameters for these elements. Based on the 
Genadiy Zhyrov et al., International Journal of Emerging Trends in Engineering Research, 8(6), June 2020, 2606- 2611

simulation results, the developer has opportunity to determine expected gain in the reliability of object through the maintenance (MC) of these elements. If the gain is found to be significant, the developer may decide to incur additional costs to change the design of the facility to ensure that the determinants are measured.

Therefore, the set $E_{\mathrm{mc}}$ is set taking into account decisions already made on the need for maintenance for some elements, as well as for reasons of verification feasibility inclusions in the scope of service, other elements.

Problem (1) is supposed to be solved as a sequence of partial problems in which the set of served elements is fixed. At each step, an auxiliary set is formed by adding to it one element taken from $E_{\mathrm{mc}}$. Before that, all the elements of the set $E_{\mathrm{mc}}^{+}$ are ordered in ascending order of the average operating time before the failure of the elements.

At each step, for a fixed set $E_{\mathrm{mc}}^{+}$, a partial problem of determining the optimal parameters $U_{\mathrm{mc}}^{+}$and $T_{\mathrm{c}}^{+}$satisfying the condition is solved:

$$
c_{\mathrm{e}}\left(E_{\mathrm{mc}}^{+}, U_{\mathrm{mc}}^{+}, T_{\mathrm{c}}^{+}\right) \rightarrow \min _{U_{\mathrm{mc}}, T_{\mathrm{c}}} .
$$

A solution $\mathrm{P}_{\mathrm{mc}}^{+}=\left\langle E_{\mathrm{mc}}^{+}, U_{\mathrm{mc}}^{+}, T_{\mathrm{c}}^{+}\right\rangle$that satisfies condition (4) is a conditionally optimal solution obtained provided that the set of serviced elements has a composition $E_{\mathrm{mc}}^{+}$.

When new elements $E_{\mathrm{mc}}^{+}$are added to the new elements, the failure $T_{0}$ rate should increase, and as soon as the condition is met at some step $T_{0} \geq T_{0}^{\text {req }}$, the process of finding a solution stops. The conditionally optimal solution $\mathrm{P}_{\mathrm{mc}}^{+}$ obtained in the last step is accepted as optimal solution $\mathrm{P}_{\mathrm{mc}}^{*}$.

Problem (2) is solved in a similar way, with the only difference that instead of partial problem (4) the problem is solved at each step:

$$
K_{\mathrm{ssa}}\left(E_{\mathrm{mc}}^{+}, U_{\mathrm{mc}}^{+}, T_{\mathrm{c}}^{+}\right) \rightarrow \max _{U_{\mathrm{mc}}, T_{\mathrm{c}}} .
$$

Thus, due to this technique, we have reduced the number of optimized parameters to two: $U_{\mathrm{mc}}$ and $T_{\mathrm{c}}$.

The parameter $U_{\mathrm{mc}}^{+}$is a vector of maintenance levels set for different serviced elements. The optimal values $u_{\mathrm{m} c i}^{+} \in U_{\mathrm{mc}}^{+}$ should be separate for different elements $e_{i} \in E_{\mathrm{mc}}^{+}$, as the probabilistic characteristics of the degradation process of different elements can differ significantly. The greatest influence on the choice of optimal value $u_{\mathrm{mc} i}^{+}$should be given by the value of the coefficient variations of degradation process element $v_{u i}$. On other hand, the optimal values $u_{\mathrm{mc} i}^{+}$may also depend on the frequency of monitoring $T_{\mathrm{c}}^{+}$.

\section{RESULT AND DISCUSSION}

For example, take the imaginary object Test- 1 and calculate the unit cost of operation $c_{\mathrm{e}}\left(E_{\mathrm{mc}}, U_{\mathrm{mc} i}, T_{\mathrm{c}}\right)$ at fixed $E_{\mathrm{mc}}$ and $T_{\mathrm{c}}$, and at different values $U_{\mathrm{mc} i}$, where $U_{\mathrm{mc} i}$ - is the vector in which the $\mathrm{i}$-th component varies $u_{\mathrm{mc} i}$ : $U_{\mathrm{mc} i}=\left\{u_{\mathrm{mc} 1}, u_{\mathrm{mc} 2}, \ldots, u_{\mathrm{mc} i}\right\}$.

The Test- 1 object is an example of the simplest object that has a consistent reliability structure and a constructive structure that has 6 levels of nesting, shown in the figure. 1. The total number of simple elements is 20 (indicated by circles in the figure). Elements included in the set $E_{0}$ are marked with hatching.



Figure 1: Structural structure of Test-1 object

To simplify, we include a single element in the set $E_{\mathrm{mc}}^{+}$, so that the vector $U_{\mathrm{mc} i}$ turns into a scalar $u_{\mathrm{mc} i}$.

Figure 2 shows the results of calculations in the form of graphs of dependence of indicators and on size at the fixed periodicity of control $T_{\mathrm{c}}=1000$ hours are resulted. The value $u_{\mathrm{mc} i}$ varies in range $[0,1 ; 0.95]$. 
Genadiy Zhyrov et al., International Journal of Emerging Trends in Engineering Research, 8(6), June 2020, 2606- 2611

Calculations were performed for three values of the coefficient variation $v_{u i}: 0.5 ; 0.8 ; 1.0$.

The obtained graphs clearly show that the functions $c_{\mathrm{e}}\left(u_{\mathrm{mc} i}\right)$ and $K_{\mathrm{ssa}}\left(u_{\mathrm{mc} i}\right)$ have pronounced extrema, the position of which depends on the coefficient of variation $v_{i}$. As the coefficient of variation increases, the optimal values of maintenance $u_{\mathrm{mc} i}^{+}$level are shifted to range of smaller values, approaching the level of 0.5 .

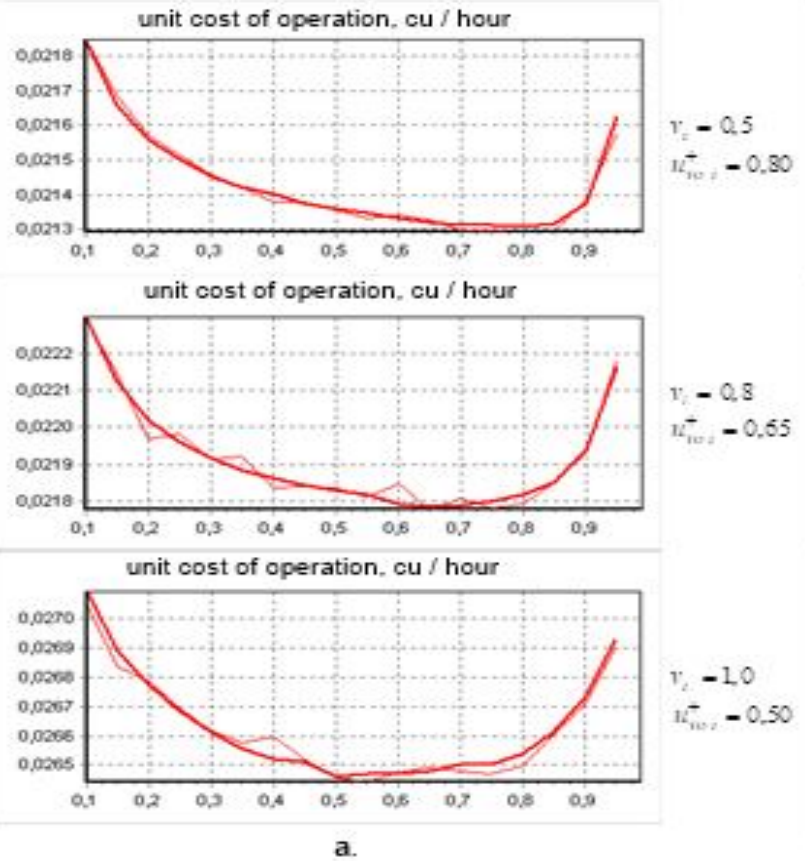

Figure 2: Graphs of functions $c_{\mathrm{e} \text { unit }}\left(u_{\mathrm{mc} i}\right)$ and $K_{\mathrm{ssa}}\left(u_{\mathrm{mc} i}\right)$ at different values $v_{i}$ (object Test-1, $\left.T_{\mathrm{c}}=1000 \mathrm{~h}\right)$

The values $T_{\mathrm{c}}$ will vary in the range from 500 to 5000 hours. Based on the results of calculations, graphs of dependence on the $T_{\mathrm{c}}$ optimal values $u_{\mathrm{mc} i}^{+}$and their corresponding values $c_{\mathrm{e}}\left(u_{\mathrm{mc} i}^{+}\right)$obtained by the criterion $\min c_{\mathrm{e}}$ (shown in the figure 3.a), and the same graphs for the values $u_{\mathrm{mc} i}^{+}$and $K_{\text {ssa }}\left(u_{\mathrm{ssa} i}^{+}\right)$obtained by the criterion $\max K_{\mathrm{ssa}}$ (shown in the figure 3.b) were constructed.
Now we need to find out whether the optimal values $u_{\mathrm{mc} i}^{+}$ depend on the frequency of monitoring $T_{\mathrm{c}}$. To do this, we make the same calculations for different values $T_{\mathrm{c}}$ of periodicity, and for each $T_{\mathrm{c}}$ we will determine the optimal values $u_{\mathrm{mc} i}^{+}$and their corresponding values $c_{\mathrm{e}}\left(u_{\mathrm{mc} i}^{+}\right)$and $K_{\mathrm{ssa}}\left(u_{\mathrm{mc} i}^{+}\right)$.
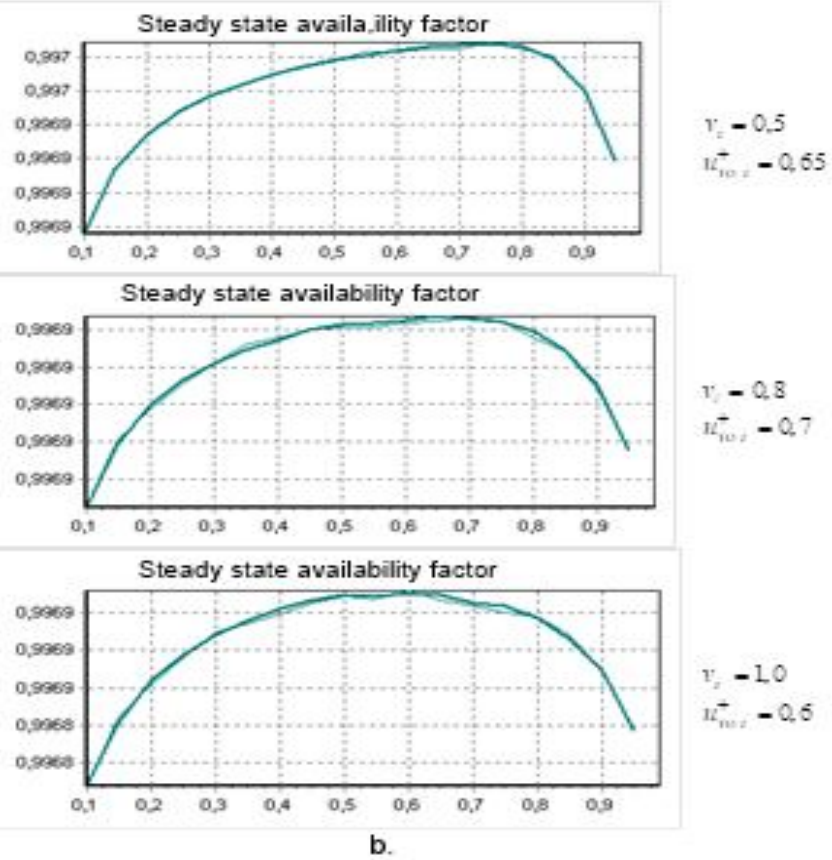
Genadiy Zhyrov et al., International Journal of Emerging Trends in Engineering Research, 8(6), June 2020, 2606- 2611

From obtained graphs we can draw the following conclusions:

- conditionally optimal values $u_{\mathrm{mc} i}^{+}$and corresponding values $c_{\mathrm{e}}\left(u_{\mathrm{mc} i}^{+}\right)$and $K_{\mathrm{ssa}}\left(u_{\mathrm{mc} i}^{+}\right)$significantly depend on periodicity of control $T_{\mathrm{c}}$ and, therefore, the values $u_{\mathrm{mc} i}^{+}$and $T_{\mathrm{c}}^{+}$are dependent;

- conditionally optimal values $u_{\mathrm{mc} i}^{+}$and $T_{\mathrm{c}}^{+}$also depend on the coefficient of variation $v_{i}$.

\section{CONCLUSION}

The article analyzes and suggests ways to optimize the maintenance process of a complex technical object. It is determined that when searching for a conditionally optimal vector $U_{\mathrm{mc}}^{+}$it is necessary to perform separate optimization for each of its elements. It is also proved that when searching for a conditionally optimal solution, it is necessary to look for compatible optimal values of the parameters $U_{\mathrm{mc}}^{+}$and $T_{\mathrm{c}}^{+}$. The results found are necessary for the development of methods and algorithms for optimizing parameters of different types maintenance.

\section{REFERENCES}

1. Lenkov S.V., Boriak, K.F., Banzak, G.V., Braun, V.O., Osypa, V.A., Pashkov, S.A., Tsytsarev, V.N., Berezovskaia, Iu.V. Prognozirovanie nadezhnosti slozhnyh obektov radiojelektronnoj tehniki i optimizacija parametrov ih tehnicheskoj jekspluatacii $\mathrm{s}$ ispolzovaniem imitacionnyh statisticheskih modelej. Odessa, VMV, 2014, 256 p.

2. Zhyrov G.B. Lenkov E.S. Algoritmichna model' protsesu tehnichnogo obslugovuvannia za stanom $z$ postiinoiu periodichnistiu kontroliu. Suchasna spetsial'na tehnika: nauk-pr. zhurn. 2017, №1(48), pp. 26-29.

3. Lenkov S., Zhyrov G., Zaitsev D., Tolok I., Lenkov E., Bondarenko T., Gunchenko Y., Zagrebnyuk V., Antonenko O. Features of modeling failures of recoverable complex technical objects with a hierarchical constructive structure. Eastern-European Journal of Enterprise Technologies. 2017, № 4/4 (88), pp.34-42.

https://doi.org/10.15587/1729-4061.2017.108395

4. Zhirov G.B. Lenkov E.S. Usovershenstvovannaia imitatsionnaia model' protsessa tehnicheskogo obsluzhivaniia i remonta slozhnogo tehnicheskogo ob\#ekta. Zhurnal Harkivs'kogo natsional'noguniversitetu Povitrianih Sil imeni
I.Kozheduba «Sistemi obrobki informatsiï». 2017, Vol.№ 3 (149), pp.14-18.

5. K.Chaabane K., A.Khatab A., E.-H. Aghezzaf E.-H., Venkatadri U., Integrated imperfect multimission selective maintenance and repairpersons assignment problem. Reliability Engineering \& System Safety, 2020, Volume 199, Article 106895. https://doi.org/10.1016/j.ress.2020.106895.

6. Duc-Hanh Dinh, Phuc Do, Benoit Iung. Maintenance optimisation for multi-component system with structural dependence: Application to machine tool sub-system. CIRP Annals, 2020, Article in pres. https://doi.org/10.1016/j.cirp.2020.04.004.

7. Ronald M. Martinod, Olivier Bistorin, Leonel F. Castañeda, Nidhal Rezg. Maintenance policy optimisation for multi-component systems considering degradation of components and imperfect maintenanceactions. Computers \& Industrial Engineering, 2018, pp. 100-112.

doi.org/10.1016/j.cie.2018.07.019.

8. Shayesteh E., Yu J., Hilber P. Maintenance optimization of power systems with renewable energy sources integrated. Energy, 2018, Volume 149, 15 April, pp. 577-586. doi.org/10.1016/j.energy.2018.02.066/

9. Radim Briš, Petr Byczanski, Radomír Goňo, Stanislav Rusek. Discrete maintenance optimization of complex multi-component systems. Reliability Engineering \& System Safety, 2017, Volume 168, December 2017, Pages 80-89. doi.org/10.1016/j.ress.2017.04.008.

10. Dmitriy Belyi, Elmira Popova, David P. Morton, Paul Damien. Bayesian failure-rate modeling and preventive maintenance optimization. European Journal of Operational Research, 2017, Volume 262, Issue 3, pp. 1085-1093. doi.org/10.1016/j.ejor.2017.04.019.

11. Manish Rawat, Bhupesh Kumar Lad. Novel approach for machine tool maintenance modelling and optimization using fleet system architecture. Computers \& Industrial Engineering, 2018, Volume 126, pp. 47-62. doi.org/10.1016/j.cie.2018.09.006.

12. Olle Wijk, Patric Andersson, Jan Block, Thord Righard. Phase-out maintenance optimization for an aircraft fleet. International Journal of Production Economics, 2017, Volume 188, pp. 105-115.

doi.org/10.1016/j.ijpe.2017.01.002.

13. YixinYe, Ignacio E.Grossmann, Jose M.Pinto, Sivaraman Ramaswamy. Modeling for reliability optimization of system design and maintenance based on Markov chain theory. Computers \& Chemical Engineering, 2019, Volume 124, pp. 381-404. doi.org/10.1016/j.compchemeng.2019.02.016.

14. Hennadii Khudov, Irina Khizhnyak, Fedor Zots, Galina Misiyuk, Oleksii Serdiuk. The Bayes Rule of Decision Making in Joint Optimization of Search and Detection of Objects in Technical Systems. International Journal of Emerging Trends in 
Genadiy Zhyrov et al., International Journal of Emerging Trends in Engineering Research, 8(6), June 2020, 2606- 2611

Engineering Research. Volume 8, No. 1, pp.7-12, January 2020.

https://doi.org/10.30534/ijeter/2020/02812020.

15. Hennadii Khudov, Irina Khizhnyak, Volodymyr Koval, Volodymyr Maliuha, Andrii Zvonko, Valerii Yunda, Viacheslav Nagachevskyi, Volodymyr Berezanskyi. The Efficiency Estimation Method of Joint Search and Detection of Objects for Surveillance Technical Systems. International Journal of Emerging Trends in Engineering Research. Volume 8, No. 3, pp.813-819, March 2020.

https://doi.org/10.30534/ijeter/2020/34832020. 